\title{
Overjustification scripts
}

\author{
STEPHEN J. DOLLINGER and RICHARD HEISE \\ Southern Illinois University, Carbondale, Illinois
}

\begin{abstract}
To test the usefulness of the script concept to the overjustification effect, college student subjects were given one of several opening story lines and asked to devise story endings to a Thematic Apperception Test (TAT) picture, and then to rate their character's intrinsic interest. Opening story lines differed in the extent to which the main character was engaging in the target activity out of intrinsic interest (standard opening) or interest plus other constraints. In two experiments (Ns $=87$ and 102), the results failed to support the prediction that the constrained-character story lines would result in less perceived intrinsic motivation than would the standard opening.
\end{abstract}

Recent theoretical discussions of the overjustification effect-the phenomenon whereby extrinsic rewards can undermine intrinsic motivation-have reconceptualized this phenomenon in terms of schemata or scripts (Eckblad, 1981; Lepper, 1981; Sandelands, Ashford, \& Dutton, 1983). Scripts are usually taken to involve cognitive representations of organized event sequences for particular contexts (Abelson, 1976, 1981). A script example related to overjustification was provided by Lepper, Sagotsky, Dafoe, and Greene (1982): "When dad says I have to finish some task before I can go out to play, that task is probably something I don't want to do" (p. 53). Applying the script concept to this phenomena implies that people may not engage in complex attributional processes but instead may unthinkingly "act out" the loss of interest in an activity when some reward or constraint is applied to motivate performance.

One way to test the viability of a script concept for overjustification research is to assess whether people in fact "possess" implicit scripts in which loss of interest follows from the imposition of extrinsic constraints such as rewards or deadlines. A natural place to look for such scripts is in Thematic Apperception Test (TAT) stories (Murray, 1943). In particular, the present study was inspired by Holt's (1978) discussion of the method for clinical interpretation of stories told to Murray's TAT Card 1 ("boy contemplating a violin'). Holt urged the clinical examiner to consider "indications of the hero's motivation for taking up and following through the study of the violin-whether it is his own motivation or induced, and if the latter, whether it 'takes' or not: does he succeed in internalizing induced motivation?' (p. 82). Thus, Holt appeared to have in mind a phenomenon quite similar to the overjustification effect: the maintenance or loss of intrinsic interest following external constraint ("induced motivation"').

To study this idea, in Experiment 1 we presented subjects with the task of devising a short story ending given one of four contrived story beginnings suggestive of in-

The authors' mailing address is: Department of Psychology, Southern Illinois University, Carbondale, IL 62901. trinsic motivation (standard), or the standard information combined with three levels of induced motivation (monetary reward, if-then contingency, and conformity information). ${ }^{1}$ These opening story lines suggested different "tracks" (Abelson, 1981) that the script might follow. After completing their stories, the subjects rated the character on variables intended to reflect intrinsic interest and musical enjoyment. On the basis of the script concept and the now extensive overjustification literature (reviewed by Deci \& Ryan, 1980, and Lepper, 1981), it was predicted that story lines detailing extrinsic constraints would lead subjects to tell stories that culminated in lower intrinsic motivation ratings than would standard opening story lines. Because the three constraints were presented in an incremental "layering" design, a second prediction was that, the more constraints on the musician in the opening story line, the less would be his (rated) intrinsic motivation at the ending. Experiment 2 replicated this method but used two forms of induced motivation (reward, if-then contingency), presented alone or in combination and compared with the standard opening story line.

\section{METHOD}

\section{Subjects and Design}

Students enrolled in the introductory psychology course participated in exchange for extra credit toward their grades. For Experiments 1 and 2 , the numbers of subjects were 87 and 102 , respectively. The subjects were assigned randomly to one of four conditions (opening story lines) in Experiment 1: standard opening; standard plus reward; standard and reward plus if-then contingency; standard, reward, and if-then contingency plus conformity to peer influence. In Experiment 2, there were five conditions: standard; standard plus reward; standard plus ifthen contingency; and two conditions presenting the standard plus both reward and if-then contingency, one with reward information first and one with if-then information presented first.

\section{Procedure}

The subjects were tested in an auditorium; data collection was planned for several unrelated projects. Data collection for the present studies was completed first. Upon arrival, the subjects found a packet of materials at their seat. Packets were assigned such that, wherever a person chose to sit, he or she had an equal chance of receiving the four story beginnings.

TAT Card 1 (Murray, 1943) was shown on an overhead screen while the subjects were given general directions to write a story. Specific direc- 
tions in the task booklet asked the subjects to write a story ending that included some information about the character's thoughts and feelings. The second page of the booklet was a blank lined sheet of $8 \frac{1}{2} \times 11$ in. paper on which the subjects were to complete the story. The third page requested several subject ratings.

The standard opening for all task booklets was "This boy is looking at his violin and is contemplating the idea of practicing his music. He has taken lessons for six months and has begun to enjoy some of his emerging skill; but sometimes he is slow to begin practicing."

For subjects in the reward groups, the opening continued with "As he contemplates practicing, he remembers that his mother promised him a $\$ 3$ bonus to his allowance if he practices five times a week."

The if-then contingency consisted of the statement " $\mathrm{He}$ is also remembering that his friends are going to play baseball this afternoon, and that he would need to finish his practice before joining them."

In Experiment 1, the subjects in Group 4 were informed of peer group influence: "Thinking of his friends reminds him of how he decided to take violin lessons-how all the kids at school wanted to take the lessons at the same time."

When finished with their story completions, the subjects turned to the last page, which, in Experiment 1, requested ratings of agreement or disagreement (5-point scales) with four statements: (1) "In 6 months, the boy will be very satisfied with his musical abilities"; (2) "In 5 years, the boy will still be playing the violin, but will do so without 'external' incentives like bonuses to his allowance"; (3) "His adult life will be significantly influenced by his violin playing"; (4) "He will appreciate fine music very much in the years ahead."

Ratings in Experiment 2 consisted of estimated probabilities (from $0 \%$ to $100 \%$ ) that (1) the boy would give up the violin in the next 6 to 12 months, (2) he would continue to play and that it would be a significant hobby in his adult life, and (3) he would play professionally or semiprofessionally. The ratings were changed to increase confidence that the results were not due to a particular format.

The subjects in Experiment 2 were also asked whether they had had any formal musical training and whether they currently played an instrument. This afforded a supplementary test of whether musical background affected the results.

\section{RESULTS}

In both experiments, the data were analyzed in one-way analyses of variance (ANOVAs).

\section{Experiment 1}

A multivariate ANOVA failed to reveal a significant condition effect $[\lambda=.82, F(12,209)=1.33, p>.10]$. The individual univariate ANOVAs also failed to offer support for the hypothesis (all Fs $<1.9$, ps $>.10$ ).

In support of the ratings' internal consistency reliability, the four variables were found to intercorrelate with rs ranging from .32 to .61 (all ps $<.001$, except the lowest value, for which $\mathrm{p}<.01$ ). Support for the ratings' validity was found when we classified the subjects' story endings according to the following scheme: character is playing violin with enjoyment; ambiguous outcome (signifying possible interest); child is playing but not enjoying it; child is not playing. As shown in Table 1, three of the four ratings were sensitive to this classification.

\section{Experiment $2^{2}$}

As in Experiment 1, the multivariate ANOVA provided no support for the hypothesis $[\lambda=.84, F(12,251)=1.44$, $\mathrm{p}>.10]$, and the univariate ANOVAs did not yield significant group effects (all Fs $<1.9$, ps $>.10$ ). Subject ratings intercorrelated at a slightly higher level than in
Table 1

Comparison of Four Story Outcomes on the Four Ratings

\begin{tabular}{lccccc}
\hline \multirow{1}{*}{\multicolumn{1}{c}{ Rating }} & \multicolumn{5}{c}{ Story Outcome } \\
\cline { 2 - 5 } & A & B & C & D & F \\
\hline 1. Satisfied with abilities & 3.2 & 3.1 & 2.5 & 2.1 & $3.4^{*}$ \\
2. Playing without bonus & 3.3 & 3.9 & 2.5 & 2.1 & $3.7^{*}$ \\
3. Violin in adult life & 2.9 & 3.7 & 2.5 & 2.1 & $3.8^{*}$ \\
4. Will appreciate music & 3.7 & 3.9 & 3.2 & 3.3 & 1.3 \\
\hline
\end{tabular}

Note-Story outcomes were as follows: (1) child is playing violin and enjoying it; (2) whether child is playing and/or enjoying it is ambiguous; (3) child is playing and not enjoying it; (4) child is not playing the violin. $N s=40,15,25$, and 7, respectively. Ratings range from 1 to 5 . See text for exact wording of rating items. $*_{p}<.05$.

Experiment 1, with $|\mathrm{r}| \mathrm{s}$ ranging from .51 to .74 (all ps $<.001)$.

Answers to the questions on the subjects' own musical training allowed a classification into those with (1) no formal training on an instrument (the "untrained"), (2) past training, but currently not playing any instrument (the "quitters"), and (3) those with training who had continued to play some instrument (the "continuers"). The numbers of subjects per cell for these groups were 34 , 46 , and 21 , respectively. This grouping was crossclassified with experimental condition for supplementary ANOVAs. Although no significant interactions emerged, a main effect on the first rating indicated that the quitters (mean $=61 \%$ ) thought that their story character was more likely to quit than did the untrained and the continuers [mean $=42 \%$ and $46 \%$, respectively; $F(2,86)$ $=2.93, \mathrm{p}<.06, \mathrm{MSe}=1,129]$. On the third rating, the subjects with training thought that their story character was less likely to play professionally or semiprofessionally than did the untrained [means $=34 \%$ for the untrained, and $18 \%$ and $22 \%$ for quitters and continuers, respectively; $\mathrm{F}(2,86)=3.80, \mathrm{p}<.05, \mathrm{MSe}=678]$. Presumably, the trained subjects were more aware of the improbability of eventually playing for remuneration.

Descriptive statistics for both experiments are shown in Table 2. These data show that, as a group, our subjects thought that the character was mildly unlikely to be satisfied with his abilities or to play in adult life (very unlikely to play for remuneration), but moderately likely

Table 2

Descriptive Statistics for Both Experiments

\begin{tabular}{lcc}
\hline \multicolumn{1}{c}{ Rating } & Mean & SD \\
\hline \multicolumn{1}{c}{ Experiment 1} & \\
Satisfied with abilities & 2.9 & 1.1 \\
Playing without bonus & 3.2 & 1.2 \\
Violin in adult life & 2.9 & 1.3 \\
Will appreciate music & 3.6 & 1.2
\end{tabular}

Experiment 2

$\begin{array}{lll}\text { Probability of quitting } & 51 & 35 \\ \text { Probability of hobby } & 43 & 30 \\ \text { Probability of pro/semipro } & 24 & 27\end{array}$

Note-See text for exact wording of items. Probabilities in Experiment 2 were expressed as percentages. 
to appreciate fine music as an adult. Whereas the subjects in Experiment 1 thought that the story character was more likely to be playing without a bonus (mean $=3.21$, where 3 is the midpoint), slightly more than half of those in Experiment 2 thought the character would quit within 1 year.

\section{DISCUSSION}

The results offer no support for the predicted effect of opening story lines on the ratings that subjects provided after completing their stories. This is particularly surprising for Experiment 1, given that some subjects had multiple constraints (reward, deadline, and mild "peer pressure" to begin with) that could have undermined their story character's intrinsic motivation. Moreover, the findings cannot be dismissed on the grounds that the dependent measures were unreliable and invalid, because they did relate meaningfully to each other: In Experiment 1, they related to a classification based on story outcome, and in Experiment 2 they related to the subjects' own musical backgrounds.

One possible explanation for the null findings is that people are relatively unaware of their scripts when a task requires little effort, or until some unexpected event causes more thoughtful consideration (Langer, Blank, \& Chanowitz, 1978). Hence, it may not be possible to demonstrate the effect tested here with subject ratings or with a between-groups design. Perhaps it could be tested by using a within-subjects design in which subjects would respond to multiple story beginnings. Another mode of testing the concept could consist of presenting multiple story beginnings and endings and assessing whether subjects systematically match up a constraint beginning with a loss-of-interest ending. Such findings would be consistent with Abelson's (1976) claim that, in organizing comprehension, scripts can result in a gap-filling phenomenon.

Future work should also attempt to dissect the story-making process to determine whether subjects' story endings are influenced by story beginnings. We attempted to do this by rating the story characters' perceived enjoyment, freedom, and intrinsic motivation. These judgments correlated significantly with the subjects' ratings. But only the perceived intrinsic motivation judgment yielded statistically significant condition main effects (which did emerge in both studies). However, these data are particularly weak because they could have resulted from the mere restatement of the reward contingency in the story completion.

Finally, before the hypothesis is rejected, further studies should be undertaken with subjects who have had more direct experience with the immediate stimulus situation (e.g., children who are beginning to study music). Studies using stimulus situations other than musical interest would also be appropriate.

\section{REFERENCES}

Abelson, R. P. (1976). Script processing in attitude formation and de- cision making. In J. S. Carroll \& J. W. Payne (Eds.), Cognition and social behavior (pp. 33-45). Hillsdale, NJ: Erlbaum.

Abelson, R. P. (1981). Psychological status of the script concept. American Psychologist, 36, 715-729.

DeCI, E. L., \& RyAN, R. M. (1980). The empirical exploration of intrinsic motivational processes. In L. Berkowitz (Ed.), Advances in experimental social psychology (Vol. 13, pp. 39-80). New York: Academic Press.

ECKBLAD, G. (1981). Scheme theory: A conceptual framework for cognitive motivational processes. London: Academic Press.

HolT, R. R. (1978). A normative guide to the use of the TAT cards. In R. R. Holt (Ed.), Methods in clinical psychology: Projective assessment. (Vol. 1, pp. 77-122). New York: Plenum.

Langer, E., Blank, A., \& Chanowitz, B. (1978). The mindlessness of ostensibly thoughtful action: The role of "placebic" information in interpersonal interaction. Journal of Personality and Social Psychology, 36, 635-642.

LEPPER, M. R. (1981). Intrinsic and extrinsic motivation in children: Detrimental effects of superfluous social controls. In W. A. Collins (Ed.), Aspects of the development of competence: The Minnesota Symposium on Child Psychology (Vol. 14, pp. 155-214). Hillsdale, NJ: Erlbaum.

Lepper, M. R., Sagotsky, G., Dafoe, J. L., \& Greene, D. (1982). Consequences of superfluous social constraints: Effects on young children's social inferences, and subsequent intrinsic interest. Journal of Personality and Social Psychology, 42, 51-65.

Murray, H. A. (1943). Thematic Apperception Test manual. Cambridge, MA: Harvard University Press.

Sandelands, L. E., Ashford, S. J., \& Dutton, J. E. (1983). Reconceptualizing the overjustification effect: A template-matching approach. Motivation and Emotion, 7, 229-255.

\section{NOTES}

1. Although it resembles a kind of deadline, the term "if-then contingency" (following the terminology of Lepper et al., 1982) more appropriately describes the requirement to practice before engaging in another activity. Also note that the information in the conformity condition was intended to raise the possibility that the story character was beginning to wonder about his initial task engagement: whether it was out of musical interest (intrinsic motive) or to follow the group (extrinsic motive).

2. Because the subjects were not identified by sex in Experiment 1 , tests for sex differences were not possible. In Experiment 2, supplementary analyses revealed no significant sex differences or any interactions of sex and experimental condition.

(Manuscript received for publication December 3, 1984.) 